\section{Dr Allen Hughes}

Dr Allen Hughes, originally from England, died in a light aircraft on Tuesday 27 November 2001, at Toowoomba, Queensland, Australia. Dr Hughes was leading a team that was intending to visit a rural area for purposes of service provision. All on board the light aircraft died. They were: Dr Hughes, the pilot, the team psychologist and a young woman doctor who had recently been accepted on to the training programme of the Royal Australian and New Zealand College of Psychiatrists. Dr Hughes leaves behind his wife Vanessa, who is pregnant, and his family of origin.

J. D. Thompson

\section{Death announcements}

We would like to note the sad deaths of the following Members and Fellows of the College in 2000 and 2001 :

\section{Dr Dashper James Arkle}

Professor Alfred Auerback

Dr David Arthur Bennett

Dr Isabella Patricia Brown

Dr Doris Elizabeth Bunbury

Dr Diana Rosamund Eryl Butler

Dr Louis Yang Ching

Sir Gilbert Ridley Debenham

Professor Nicholas Destounis

Dr Howard James Llewellyn Dickinson

Dr Daksha Pravin Emson

Dr Timothy Laurence Foley

Professor Arnold Jerome Friedhoff
Dr William Hewitt Gillespie

Dr Kenneth Dewar Hopkirk

Dr John Gotea-Loweg

Dr Keith Edward Jones

Professor Julian Katz

Professor Ramesh Kumar

Dr Charles Symes Lindsay

Dr Betty Emma Anna Magill

Dr Robert Kenneth McAll

Dr Duncan Alexander McRae

Dr Baiju Ishwarlal Naik

Dr Mary O’Brien

Dr Victor Osasikemwen Oviasu

Dr India Rikh

Dr Lawrence Sharp

Dr William Bennett Spry

Dr Hector John Scott

\title{
reviews
}

\section{Understanding Clinical Papers}

By David Bowers, Allan House and David Owens.

Chichester: Wiley. 2001

202 pp. f $19.95(\mathrm{pb})$

ISBN: 0-471-48976-X

\section{Critical Reviews in Psychiatry}

Edited by Tom Brown and Greg Wilkinson (2nd edn).

London: Gaskell. 2000

278 pp. $\mathrm{f} 18$

ISBN: 1-901242-41-2

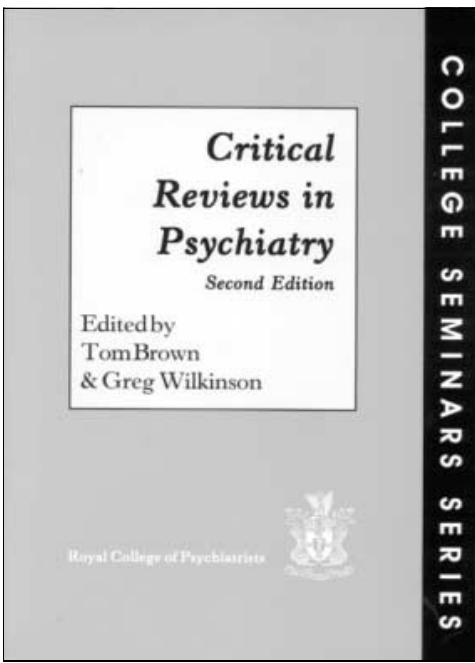

With the introduction of the 'critical reading' paper in the MRCPsych examination one might have expected a plethora of texts on the subject. This has not been the case and many anxious trainees scramble to find appropriate texts to help prepare for the examinations. Many of their trainers struggle to assist and despite the suggestions to orientate journal clubs for critical appraisal, many remain insufficient for the purpose. Will either of these books be of assistance?

Critical Reviews in Psychiatry offers a simple solution: let the trainees practise. The past papers offer them an opportunity to see how others may have struggled and succeeded in previous examinations. The other papers with their set questions and model answers give them an opportunity to practise, an invaluable part of the exam preparation. The model answers might be better placed separately from the questions to reduce temptation to look at the answers when the going gets too difficult. The book could be enhanced by providing an additional section on guided analysis and criticism of the papers, which may deepen understanding.

However, is this book sufficient? No but the addition of Understanding Clinical Papers may help. This book, aimed at a general health audience, provides 30 short chapters on a range of topics from reading the introduction of a paper to interpreting graphs and tables, basic designs, numbers and statistics. The book is written in a clear, chatty style and covers many concepts important for understanding research papers that often remain an enigma to trainees (e.g. odds ratios, number needed to treat, confidence intervals, epidemiological fallacy). Its many examples taken from published papers from many areas of clinical medicine are enhanced by the use of text bubbles designed to clearly identify key points the authors wish to make. The book covers some statistical tests not often dealt with in books of such length for example, logistic and Cox regression and survival analysis. Inevitably in a book of such brevity covering a large area, difficult topics are not covered in any depth and it would have been helpful if the authors had referred to other texts that cover the concepts more thoroughly.
The book does not directly deal with experimental design and method and quasi-experimental design, areas of central importance in understanding much of clinical research, nor does it cover single case designs. One small gripe with the book is that its title, Understanding Clinical Papers, is misleading. The book may assist in understanding clinical research papers, but it goes beyond this and provides an understanding of a range of important research-related topics useful to trainees and others.

Jed Boardman Senior Lecturer in Social Psychiatry, Guy's, King's and StThomas' Medical School, King's College London

\section{Psychiatry in Multicultural Britain}

Edited by Dinesh Bhugra and Ray Cochrane. London: Gaskell. 2001. 367 pp. $f 30.00(\mathrm{pb})$. ISBN: 1-901242-45-5

Psychiatry

in Multicultural Britain

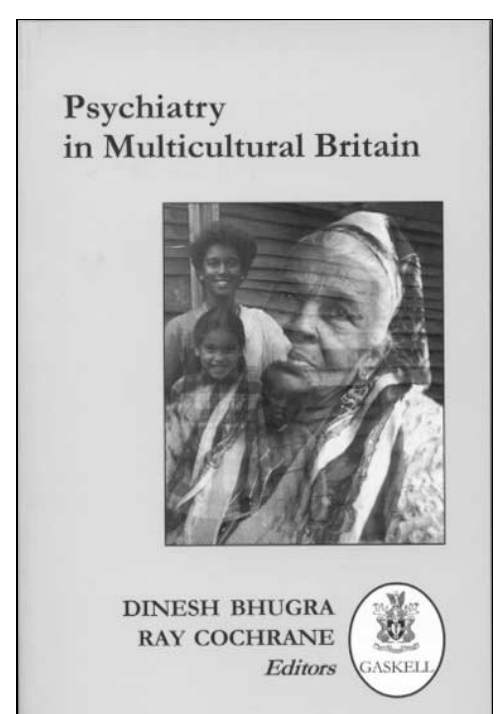

DINESH BHUGRA RAY COCHRANE Editors 